\title{
Concepções dos alunos de graduação em enfermagem sobre o envelhecimento
}

\author{
BELIEFS OF UNDERGRADUATE NURSING STUDENTS ON AGING \\ CONCEPCIONES DE LOS ALUMNOS DE PRE GRADO EN ENFERMERÍA \\ SOBRE EL ENVEJECIMIENTO
}

\author{
Noely Cibeli dos Santos ${ }^{1}$, Paolo Meneghin ${ }^{2}$
}

\section{RESUMO}

Este estudo teve como objetivo identificar as concepções do aluno de graduação em enfermagem sobre o envelhecimento. Pesquisa qualitativa foi realizada na Universidade Cidade de São Paulo, com 49 alunos que escreveram uma dissertação com o tema "O que é ser velho?". Foi realizada análise de conteúdo, nas quais foram identificadas três unidades temáticas: Representações do ser velho, Como percebe o velho na sociedade e família e Necessidade de mudança de opinião pública. Os resultados mostraram que o aluno traz em sua concepção muitas imagens negativas do envelhecimento e evidencia a necessidade de mudanças na sociedade e na família.

\section{DESCRITORES}

Envelhecimento.

Educação em saúde.

Estudantes de enfermagem.

\section{ABSTRACT}

The objective of this study was to identify the conceptions of undergraduate Nursing students on aging. A qualitative research was carried at the Cidade de São Paulo University (Unicid); 49 students were requested to write a text whose theme was "what does being old mean?". The texts were submitted to a content analysis, in which three thematic units were identified: Representations of the old being; How respondents perceive old the elder in society and within the family; and the Need to change public opinion regarding aging. The results showed that conceptions of the students on aging are tied to negative images and showed the need for changes in the society and in the family.

\section{KEY WORDS}

Aging.

Health education.

Students, Nursing.

\section{RESUMEN}

En este estudio se tuvo como objetivo identificar las concepciones del alumno de pregrado en enfermería sobre el envejecimiento. Se trata de una investigación cualitativa realizada en una Universidad de la Ciudad de Sao Paulo, con 49 alumnos que escribieron una texto con el tema “Qué es ser viejo?’. Fue realizado un análisis de contenido, en las que fueron identificadas tres unidades temáticas: Representaciones del ser anciano, Cómo perciben al anciano la sociedad y la familia y Necesidad de cambio de la opinión pública. Los resultados mostraron que el alumno trae en su concepción muchas imágenes negativas del envejecimiento y evidencia la necesidad de cambios en la sociedad y en la familia.

\section{DESCRIPTORES}

Envejecimiento.

Educación en salud.

Estudiantes de enfermería.

\author{
1 Enfermeira Espe- \\ cialista. Docente da \\ Faculdade de Enfer- \\ magem da Universi- \\ dade Cidade de São \\ Paulo(UNICID). \\ Aluna do Programa \\ de Pós-graduação \\ em Enfermagem na \\ Saúde do Adulto, \\ nível mestrado, da \\ Escola de Enferma- \\ gem da Universidade \\ de São Paulo (EEUSP). \\ 2 Professora Doutora \\ do Departamento de \\ Enfermagem Médico- \\ Cirúrgica da EEUSP. \\ paolomen@usp.br
}




\section{INTRODUÇÃO}

A formação do aluno de graduação em enfermagem é marcada por várias experiências que levam a reflexões pessoais. Essas experiências são difíceis de serem trabalhadas pois, diferentemente dos conteúdos teóricos, trazem um contato com as próprias concepções que necessitam ser reconhecidas.

Dentre estas situações complexas está o contato com o cliente idoso, com doentes crônicos e terminais. O cuidar do idoso pode ser muito interessante quando o foco de atuação retrata idosos sadios, ativos e felizes, que participam de grupos. Porém, muitas vezes, cuidamos de idosos hospitalizados ou institucionalizados e, neste caso, o cuidado pode ser marcado por sofrimento, perdas, morte e, principalmente, relações familiares perturbadas.

Todas estas questões, no currículo de graduação, são apresentadas ao aluno com o enfoque nos conteúdos da fisiopatologia do envelhecimento. Os sentimentos emergidos neste contexto, na maioria das vezes, não são trabalhados e até mesmo reprimidos, sem considerar as diferentes histórias de vida. Nesse contexto, as necessidades dos alunos não são atendidas e objetivos de aprendizagem também não são alcançados.

Aprofundar-se nestas questões torna-se de grande relevância em decorrência do aumento do número de idosos no Brasil. Essa crescente demanda, relacionada ao aumento do número de idosos, traz a necessidade de formação e capacitação específica para todos que atuam na formação dos profissionais dos serviços de saúde e sociais, bem como capacitação dos profissionais atuantes, através de programas de treinamento específicos para o cuidado ao idoso, produzindo, como resultado, um profissionalismo mais atuante e renovado, que aborde os aspectos éticos, técnicos e políticos, consolidando uma ética de qualidade, a busca de competência técnica e o compromisso político com resultados, efetividade e respeito aos cidadãos idosos ${ }^{(1)}$.

Vários autores citam a influência da forma de como o envelhecimento é abordado durante a graduação na determinação de muitas das atitudes dos alunos em relação ao envelhecimento $^{(2-6)}$.

A qualidade e a quantidade do conteúdo sobre envelhecimento abordado afeta diretamente o cuidado do idoso e, por isso, há necessidade de pesquisas sobre o que é ensinado, como é ensinado, o tempo dispensado ao assunto, e qual a importância desse conteúdo no currículo ${ }^{(2)}$.
Há necessidade de estudos qualitativos que busquem conhecer as influências desses conteúdos na formação de opinião dos estudantes e acrescentam a necessidade de se estudar estratégias de ensino/aprendizagem, que tenham um impacto positivo no conhecimento e na atitude do aluno para com o idoso ${ }^{(5,7)}$.

A revisão de literatura sobre o tema ressalta haver uma preocupação na construção dos currículos em Geriatria e Gerontologia, tendo como enfoque os conteúdos programáticos. Acredita-se, porém, que seja necessário acrescentar a essa preocupação o conhecimento das concepções do aluno sobre o envelhecimento e como estas influenciam seu processo de aprendizagem ${ }^{(8-13)}$.

Neste sentido, um dos fatores principais para adequação do ensino do processo de envelhecer é conhecer as concepções dos alunos sobre o envelhecimento, entendendo e predizendo seu comportamento em relação ao idoso neste contexto.

Diante das considerações e tendo como foco uma abordagem humanizada do aluno, colocamos os seguintes questionamentos: quais são as concepções do aluno sobre o envelhecimento? Qual o seu conhecimento, suas crenças e seus valores neste sentido? Qual a influência da sociedade na construção de sua concepção sobre o tema central? Conhecer as respostas para estas questões, em nossa sociedade, onde o número de idosos está crescendo, é fundamental para que o processo de aprendizagem tenha como meta o crescimento pessoal, através de experiências significativas que desenvolvam a capacitação técnica e uma formação humanista, pois desse modo poderemos conhecer o que deve ser repensado e o que pode ser potencializado no aluno.

\section{OBJETIVOS}

\section{Objetivo geral:}

- Identificar as concepções do aluno de graduação em enfermagem sobre o processo de envelhecimento.

\section{Objetivos específicos:}

- Verificar o seu conhecimento sobre o envelhecimento.

- Identificar suas crenças e valores sobre o envelhecimento.

- Conhecer sua percepção sobre a relação da sociedade com o envelhecimento. 


\section{TRAJETÓRIA METODOLÓGICA}

Dada a natureza dos objetivos, o estudo foi realizado utilizando-se uma metodologia qualitativa de pesquisa.

\section{Campo da pesquisa}

A pesquisa foi realizada na Universidade Cidade de São Paulo - UNICID - após aprovação do Comitê de Ética dessa Universidade.

\section{População}

A população é constituída por alunos que cursam a disciplina "Enfermagem em situações clínicas e cirúrgicas". Essa disciplina faz parte da grade curricular do terceiro ano do curso de graduação em enfermagem.

\section{Critério de inclusão}

Foram incluídos, no estudo, os alunos que concordaram em participar, após terem sido informados sobre os objetivos da pesquisa, sendo-lhes dada a garantia de anonimato e de que sua participação não representaria ganhos ou prejuízos (oficializado através de assinatura no termo de consentimento livre esclarecido).

Por tratar-se de um grupo pré-estabelecido (alunos do terceiro ano), e a coleta de dados fazer parte de uma abordagem pedagógica, a proposta foi feita para todos alunos. $\mathrm{O}$ número total de alunos em sala de aula, neste dia era de 82 , porém 49 alunos realizaram todas etapas da coleta de dados. Apesar de ser uma pesquisa qualitativa, onde o critério de exaustão determina o número da amostra, optamos por trabalhar com os 49 alunos garantindo maior confiabilidade dos dados.

\section{Coleta de dados}

A coleta de dados foi realizada em sala de aula durante a primeira abordagem sobre o processo de envelhecer, sendo composta de quatro etapas:

1. Identificação dos sujeitos: preenchimento de questionário com dados relativos à caracterização dos aluno.

2. Estratégia de estímulo: audição da música "O homem velho", de Caetano Veloso, acompanhando com a letra. Essa música foi escolhida pela sua subjetividade, para suscitar o problema, pois a intenção era que o aluno, também, refletisse sobre o envelhecimento em seus aspectos psicossociais.

3. Discussão em grupo, formado pelos próprios alunos, para compartilhar e discutir diferentes opiniões, sem interferência do pesquisador.

4.Reflexão individual e dissertação sobre o tema "O que é ser velho?".

\section{Análise dos dados}

Para tratamento dos dados obtidos, foi escolhida a técnica de análise de conteúdo, por ser uma técnica possível de ser aplicada a textos escritos ou a outras formas de comunicação seja oral, visual ou gestual. O objetivo desta técnica é compreender criticamente o sentido das comunicações, seu conteúdo manifesto ou latente e as significações explícitas ou ocultas ${ }^{(14)}$.

A pesquisa qualitativa, por sua vez, pressupõe um cuidado especial por ocasião da análise dos discursos ou de relatos, pois este é um processo criativo, intimamente dependente da introspecção e capacidades conceituais do analista $^{(15)}$.

Além do preparo do analista é necessária a adoção de uma técnica que seja analiticamente rigorosa, mentalmente replicável e explicitamente sistemática. Dessa forma tornase obrigatório que o pesquisador seja metódico ao relatar, em detalhes suficientes, o procedimento de coleta e o processo empregado na análise dos dados, para permitir que a comunidade científica possa julgar a qualidade do produto resultante ${ }^{(15)}$.

A seguir, serão descritos os passos realizados para análise das entrevistas, a partir de sua transcrição, um procedimento também importante na pesquisa qualitativa, pois o pesquisador através da transcrição, mantém novo contato com os dados coletados (...), permitindo uma re-leitura dos dados vividos, gravados e transcritos, e assim, a percepção de detalhes aparentemente sem importância ${ }^{(16)}$.

Neste sentido, é importante para o pesquisador, determinar algumas questões norteadoras para a análise das entrevistas $^{(17)}$. Desta forma, foram elaborados os seguintes questionamentos:

1. Como a velhice aparece nas dissertações?

2. Que significados são atribuídos à velhice?

3. Como é interpretada a relação da família e da sociedade com o velho?

4. De que forma os conceitos e normas sociais influenciam sua representação da velhice?

É importante, ainda, destacar os seguintes questionamentos:

1. O que é enfatizado pelos sujeitos?

2. O que não é dito explicitamente?

3. O que está implícito?

4. Aparecem contradições?

5. Como as contradições se manifestam? 
Estabelecidas as indagações, iniciaram-se as leituras e releituras sucessivas de todas as dissertações e a seguir, cada dissertação foi retomada para análise individual. Durante a leitura, os significados que se destacavam e que respondiam direta ou indiretamente aos questionamentos propostos, eram grifados no texto e grafados à sua margem para facilitar a realização de comparações e assim, continuar procedendo à confirmação de codificações já estabelecidas ou criação de novas unidades de significado, se assim fosse necessário ${ }^{(17)}$, como exemplificado a seguir:

\begin{tabular}{|c|c|c|}
\hline Trecho da dissertação & $\begin{array}{c}\text { Destaque dos } \\
\text { sentidos/significados }\end{array}$ & $\begin{array}{l}\text { Codificação das unidades de } \\
\text { significado }\end{array}$ \\
\hline $\begin{array}{l}\text { Ser velho: tudo muda desde o corpo até } \\
\text { sua mente a alma. O tempo passou e a } \\
\text { vida começa ser vista de outra forma. Há } \\
\text { momentos que se sente sozinho, acho } \\
\text { que quan do estão neste momento de } \\
\text { lembranças do que viveram. É recordados } \\
\text { momentos felizes que são destacados. Per- } \\
\text { cebe que tudo que viveu foi um momento } \\
\text { único. No seu corpo físico tudo mudou, } \\
\text { cabel os brancos, visão não tão perfeita, já } \\
\text { não vê as coisas com tanto entusiasmo e } \\
\text { vigor; }\end{array}$ & $\begin{array}{l}\text { - sofrer perdas físicas } \\
\text { - ver a vida de modo diferente } \\
\text { - ter solidão } \\
\text { - viver de lembranças }\end{array}$ & $\begin{array}{c}\text { Impacto na vida } \\
\downarrow \\
\text { Viver as conseqüências da vida que } \\
\text { tiveram } \\
\downarrow \\
\text { Representações do "ser velho" }\end{array}$ \\
\hline
\end{tabular}

Buscou-se, então, identificar os significados que eram mais comuns e que apareciam com maior freqüência, inicialmente em cada discurso, e, posteriormente, na comparação com aqueles que emergiam nos demais discursos. Para os significados que eram comuns foi estabelecida uma codificação, que foi chamada de unidade de significado ${ }^{(17-18)}$.

Todo o material foi lido e relido, várias vezes, para confirmar as codificações já estabelecidas ou criar novas unidades de significado. Cada unidade de significado foi submetida à análise de um outro pesquisador com experiência nesta metodologia, para determinar o nível de concordância das codificações, que quando concordantes eram mantidas e em caso de discordância era estudada uma nova codificação.

\section{RESULTADOS}

\section{Caracterização da população}

O grupo de 49 alunos estudados caracterizou-se pelo predomínio do sexo feminino $(95,9 \%)$, idade compreendida entre 19 e mais de 40 anos, sendo que 59,2\% apresentavam idade entre 19-25 anos.

Quanto à naturalidade, o grupo estudado, em sua maioria era da região sudeste $(93,9 \%)$ e as outras regiões citadas foram norte e nordeste. As religiões predominantes foram a católica $(67,4 \%)$ e evangélica $(20 \%)$.

Em relação ao vínculo empregatício, 53,1\%, eram trabalhadores da área de saúde, sendo que a maioria $(61,6 \%)$, atuava no setor de clínica médica e, portanto, com clientes adultos.

No que se refere ao trabalho com idoso observou-se que a maioria $(65,3 \%)$ referiu já ter trabalhado com esta clientela.
Os alunos que não trabalham na área de saúde, responderam a partir de suas experiências em estágios realizados na graduação. Em relação à convivência, também a maioria, $(65,3 \%)$ relatou conviver com idosos.

\section{Análise de conteúdo das dissertações}

Os textos foram analisados à luz das indagações propostas, buscando-se identificar os significados que eram comuns e que apareciam com maior freqüência, inicialmente em cada dissertação, e, posteriormente, comparando-os com aqueles que emergiram nas demais dissertações. Aos significados que eram comuns estabelecemos uma codificação, que foi chamada de unidade de significado.

A análise dessas unidades, então, convergiu para 3 unidades temáticas centrais: Representações do ser velho, Percepção da velhice na família e na sociedade e Necessidade de mudança de opinião pública.

As unidades temáticas e suas respectivas unidades de significado reproduzem o que foi expresso de modo explícito ou não, as contradições, e a relação das unidades entre si. O resultado final da análise foi ilustrado através de esquemas que contribuíram para a compreensão dos significados apreendidos, a partir da dissertação dos alunos, acerca do que é ser velho e qual a relação da sociedade com o envelhecimento.

\section{Unidade temática: Representações do ser velho}

Para o aluno, o ser velho é conseqüência da vida que tiveram e o conteúdo das dissertações apontam três caminhos que podem representar a velhice: a não aceitação do processo de envelhecer, ter o envelhecimento como desafio e aceitá-lo como um processo da vida. 
A não aceitação do processo de envelhecer está vinculada às perdas que o envelhecimento traz e suas conseqüências, não visualizando uma possibilidade de adaptação ou crescimento. É citada a perda física, a dependência e o abandono da família.

A solidão está presente não apenas pelo abandono da família, mas também pela perda de pessoas amadas. A desvalorização é marcada pelo não reconhecimento da experiência, das potencialidades e da sua capacidade de manter a autonomia, tendo em vista apenas a dependência.

A perda do entusiasmo e a tristeza estão diretamente relacionadas com a solidão, a desvalorização e a dependência física e psíquica, o que traz a desilusão e as emoções passam a ter outro significado devido a tudo que viveu.

Por já ter passado por todas as fases de desenvolvimento e por muitas perdas, pode sentir-se cansado da própria vida, ver na morte a solução ou temer o futuro.

Ter o envelhecimento como desafio é representado pela necessidade de adaptar-se às perdas físicas que levam à dependência, à falta de respeito, de valorização e a todas as dificuldades do processo de envelhecer. Para tanto tenta cuidar o máximo da saúde e buscar um novo significado para vida. Percebe a necessidade de ser útil e reconhece o idoso como um serforte.

Ainda neste processo, o idoso encontra na espiritualidade, uma forma de preparar-se para morte. Saber que será lembrado, que deixou um pouco de si em seus descendentes, também é visto como uma forma de enfrentar o envelhecimento.

Aceitar o processo de envelhecer é reconhecer fatores positivos do envelhecimento, superando ou adaptando-se às dificuldades. Esses fatores são identificados como a experiência adquirida, a sabedoria, ter a vida concretizada, buscar o desenvolvimento, de viver com suas lembranças positivas ou negativas, sabendo usá-las no presente para enfrentar a sua realidade.

O aluno reconhece as dificuldades do envelhecer, suas conseqüências, a dificuldade de adaptação, mas também visualiza a possibilidade de um envelhecer com realizações. O importante é destacar que há ligações possíveis entre estes caminhos, como apresentado à figura 1.

\section{Unidade temática: \\ Percepção da velhice na família e na sociedade}

Quando os alunos se referem à família, nas dissertações, são identificados dois tipos de idosos: o útil e o dependente. O idoso útil é aquele que realiza "favores" para a família, serviços secundários, não sendo evidenciado uma relação de afetividade ou a intenção de proporcionar ao idoso o sentimento de realização.
Em relação ao idoso dependente é citada a dificuldade de adaptação às modificações que o envelhecimento traz e o conseqüente afastamento. $\mathrm{O}$ idoso é visto como um "peso" para a sua família, que já tem suas responsabilidades e não prioriza o cuidado ao idoso, sendo que algumas famílias “ $O$ largam” no asilo. $\mathrm{O}$ asilo não é considerado como uma possibilidade de cuidado, mas como sinônimo de abandono, evidenciando a influência da visão estigmatizada que esta instituição desperta na sociedade.

Por outro lado, o aluno reconhece que a família traz felicidade ao idoso quando dá apoio, reconhecendo a sua importância no processo de envelhecer.

Em relação à sociedade é citado que a mesma $o$ considera importante, mas não o inclui, ou seja, possui um discurso da valorização do idoso, mas na prática não oferece condições para o seu desenvolvimento. O aluno reconhece ainda que a cultura, a política e a situação econômica transformam o idoso em problema para sociedade e para a família, à medida que não consideram a sua contribuição, não reconhecem que podem aprender com o idoso e o desvalorizam por não produzir.

É enfatizado que apesar do conhecimento e experiência, o idoso é desvalorizado, desprezado e rejeitado. Para o aluno, a sociedade nega o processo de envelhecer quando não considera a contribuição do idoso, esquece que irá envelhecer e não reconhece que pode aprender com o idoso. Todo este desvalor pode destruir a vontade de viver do idoso e a relação entre estas unidades de significado estão apresentadas à figura 2.

Unidade temática:

Necessidade de mudança de opinião pública.

O aluno relaciona as representações do ser velho, suas repercussões na sociedade e na família e reflete sobre as necessidades de mudança confirmando suas convicções e evidenciando que a sociedade e a família são determinantes no processo de envelhecer.

Nesse sentido, em seu discurso, é observada a urgência em reconhecer que o Brasil é um país que está envelhecendo, que necessita mudar a situação atual do idoso e ensinar o jovem a respeitá-los.

Para tanto, é necessário valorizar o idoso, incluindo-o na família e na sociedade para que possa ter participação ativa, independente de suas limitações, proporcionar dignidade e respeito aos seus diretos e, assim, promover melhor qualidade de vida, como se percebe pelo diagrama apresentado à figura 3 . 


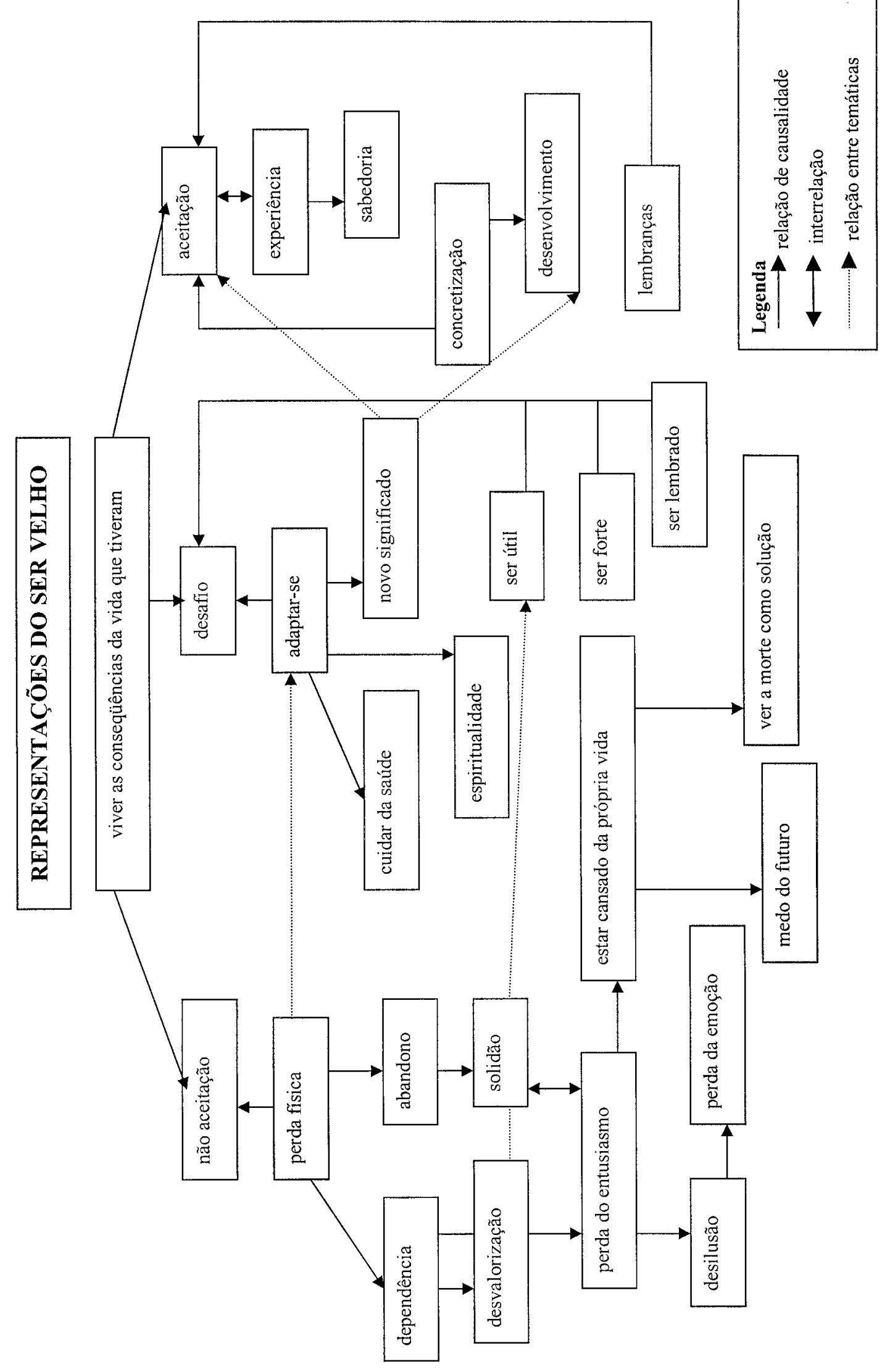

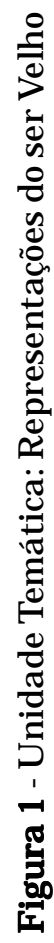




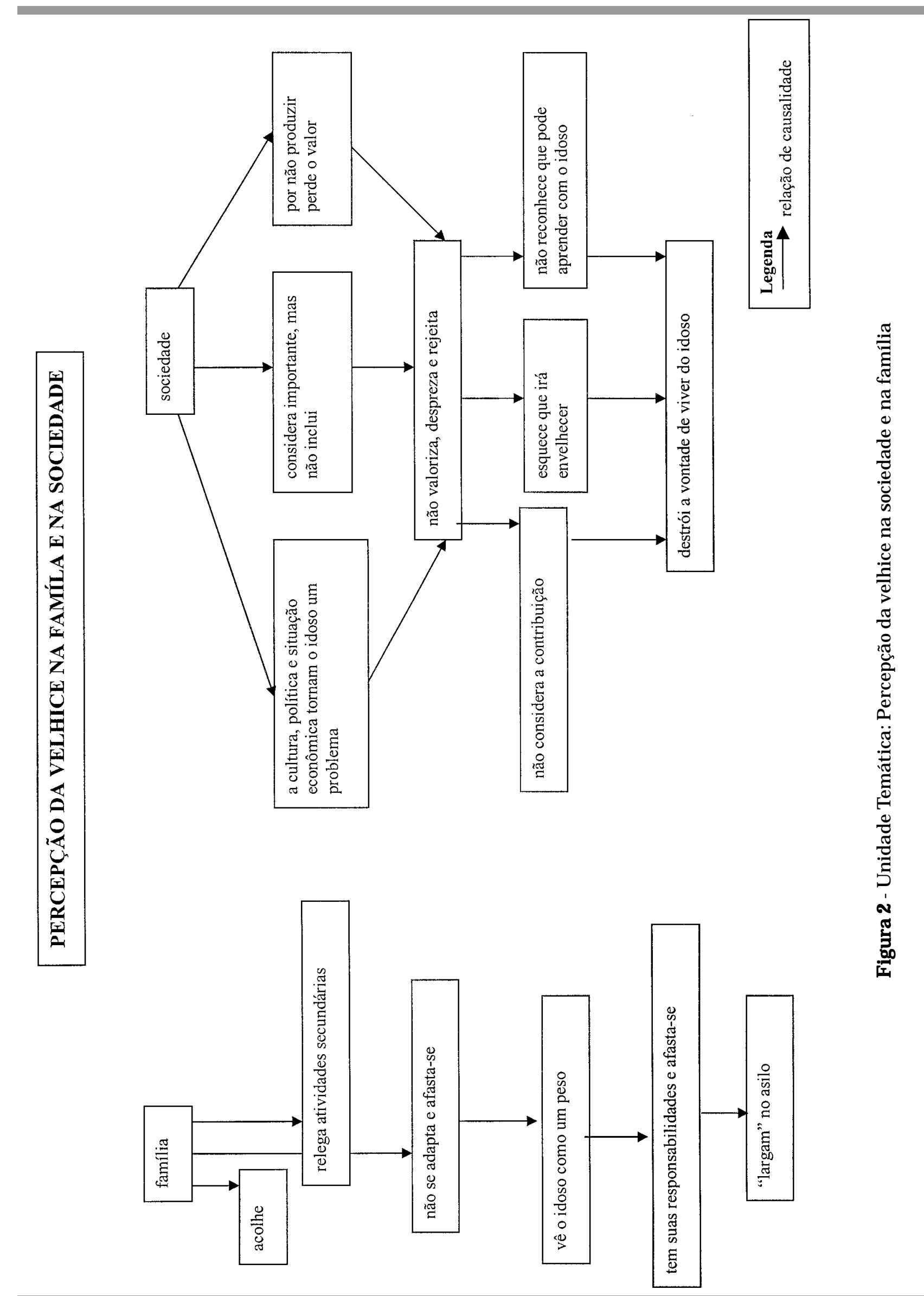




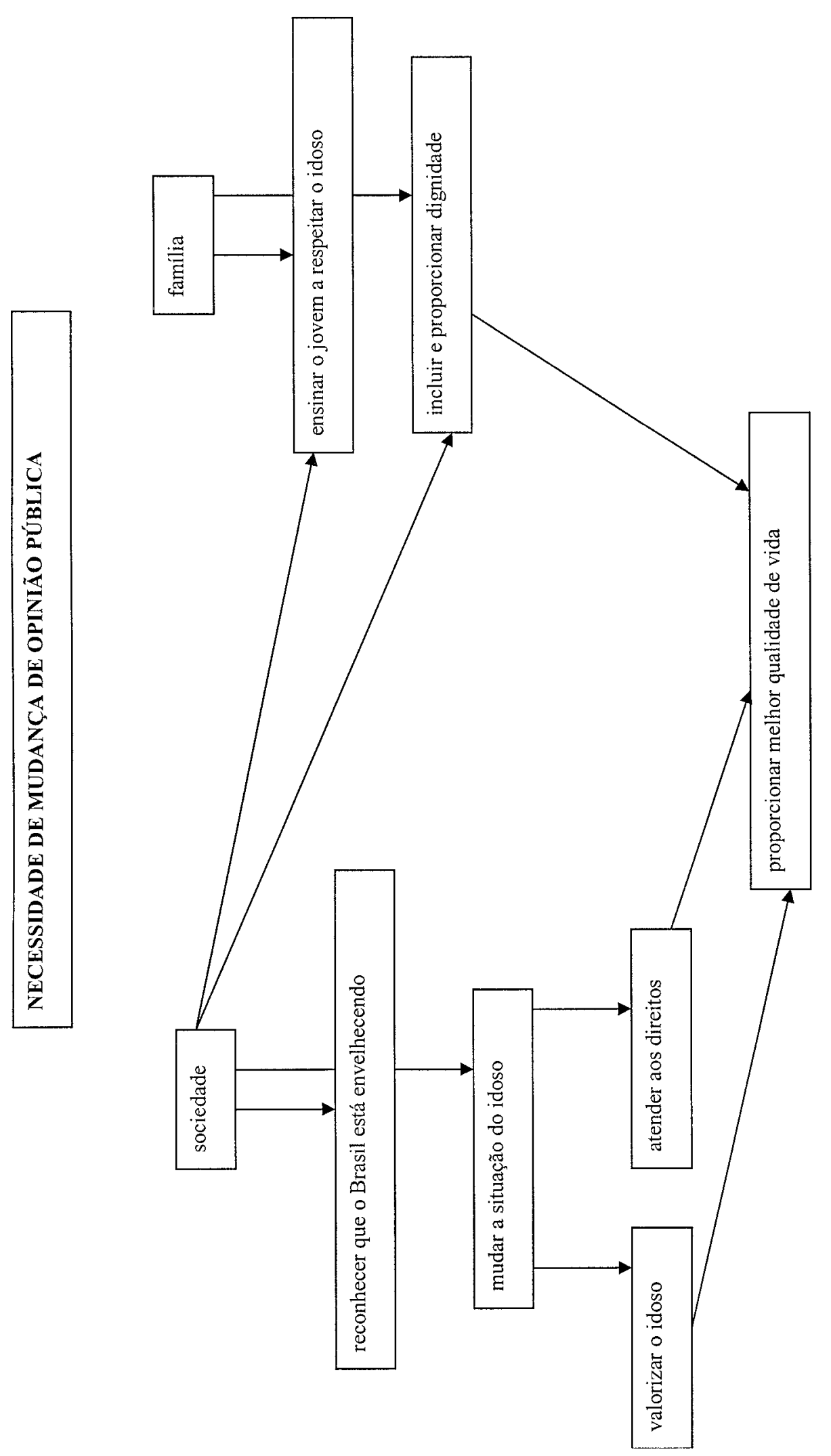

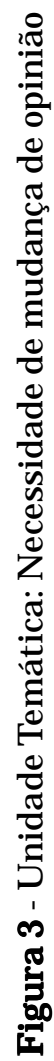




\section{CONCLUSÕES}

Este estudo evidenciou que o conhecimento do aluno sobre o envelhecimento é baseado no senso comum, ressaltando os estereótipos encontrados na sociedade tais como o de dependência, abandono, tristeza e desvalor. Poucas são as referências ao "envelhecimento com qualidade" e "às novas possibilidades de envelhecer" discutidas atualmente na sociedade.

As crenças citadas pelos participantes são referentes ao processo de envelhecer relacionando-o, quase que unicamente, a perdas. Essas perdas são relacionadas não apenas aos aspectos físicos, mas, principalmente, ao papel do idoso na família e na sociedade. Para o aluno, a família apresenta dificuldade em lidar com a dependência, o que pode ser a causa de abandono, e a sociedade, por sua vez, não valoriza o idoso. $\mathrm{O}$ envelhecimento também é visto como um desafio e uma possibilidade de ganhos, quando o mesmo é aceito como um processo natural da vida, porém, estes fatores positivos do envelhecimento ou de adaptação foram citados em menor intensidade.

Em relação à sociedade, os participantes apontam a necessidade de mudança de opinião pública. O processo de inclusão do idoso, reconhecido como fato incontestável dado o aumento da população mundial de idosos, necessita de um programa educativo de mudança de comportamento que deve se iniciar na família e se refletir, também, na modificação das

\section{REFERÊNCIAS}

(1) Silva EBN, Pereira NG, Garcia YR. A instituição e o idoso: um estudo das características da instituição e do perfil de seus moradores. Gerontologia. 1998;6(4):167-76.

(2) Malliarakis DR, Heine C. Is gerontological nursing included in baccalaureate nursing programs? J Gerontol Nurs. 1990;16(6):4-7.

(3) Santos LLC, Bub LIR, Mendes NTC. Levantamento dos conteúdos de geriatria e gerontologia dos currículos dos cursos de graduação em enfermagem de Santa Catarina e análise das atitudes em relação ao idoso apresentada por seus professores e estudantes. Rev Ciênc Saúde. 1990;9(2):75-107.

(4) Treharne G. Attitudes towards the care of elderly people: are they getting better? J Adv Nurs. 1990;15(7):777-81.

(5) Fagerberg I, Ekman SL, Ericsson K. Two studies of the new nursing education in Sweden: 1. The place of gerontology and geriatrics. 2. Student characteristics and expectations. Nurse Educ Today. 1997;17(2):150-7.

(6) Santos SSC, Lundh U. Education in gerontological nursing in Brazil and Sweden: is it possible to compare? Texto Contexto Enferm. 2001;10(2):167-84.

(7) Puentes WJ, Cayer CA. Effects of a modified version of Feeley's Campus Wellness Vacation on baccalaureate registered nurse students' knowledge of and attitudes toward older adults, J Nurs Educ. 2001;40(2):86-9.

(8) Baqueiro MB, Oliveira C. O ensino de geriatria e gerontologia na Escola de Enfermagem da Universidade Federal da Bahia. Nursing 2000;3(22):17-20. (edição brasileira) concepções sociais sobre o envelhecimento, para que se possa proporcionar melhor qualidade de vida ao idoso.

\section{CONSIDERAÇÕES FINAIS}

Este é um estudo que se originou da prática docente, de experiências vividas no ensino de graduação e, cujos resultados, pretendemos aplicá-los nesse mesmo ensino, em um movimento dinâmico de transformação da realidade. Nesse sentido podemos pensar em construir um conceito de envelhecimento, na formação dos alunos, a partir das concepções apontadas por eles mesmos. Se o conceito de envelhecer está tão associado a perdas, que realmente existem, talvez o enfoque primário, na formação profissional, devesse também incluir um trabalho desenvolvido com idosos sadios, para que o aluno vivencie uma perspectiva real e concreta de envelhecimento com crescimento e realizações.

Trabalhar com o aluno nesta perspectiva poderá proporcionar uma experiência reflexiva, tornando o contato com o envelhecimento, uma experiência gratificante, cuja vivência com idosos sadios possa auxiliar na construção de uma imagem positiva, e que possa ser aplicada por ocasião do contato do aluno, com os aspectos patológicos do envelhecer que incluem perdas, limitações, dor, sofrimento e morte, com o objetivo primordial de otimizar a qualidade de assistência de enfermagem ao idoso.
(9) Diogo MJD, Duarte YAO. O envelhecimento e o idoso no ensino de graduação em enfermagem no Brasil: do panorama atual à uma proposta de conteúdo programático. Rev Esc Enferm USP. 1999;33(4):370-6.

(10) Brêtas ACP, Yoshitome AY. A construção da área de gerontologia e geriatria no departamento de enfermagem da Universidade Federal de São Paulo: da concepção à concretização. Acta Paul Enferm. 1998; 11(n. esp.):53-6.

(11) Posso MBS, Sbambatti, MS, Savonitti BHRA, Piage CD, Hupsel Z. Enfermagem gerontológica e geriátrica: proposta para seu ensino na graduação. Âmbito Hosp. 1996;4:25-8.

(12) Duarte YAO. A influência da formação acadêmica do enfermeiro na assistência ao idoso. Âmbito Hosp. 1994;9:61-6.

(13) Rodrigues RAP, Mendes MMR. Enfermagem geronto-geriátrica: proposta curricular. Rev Paul Enferm 1993;12(2):78-81.

(14) Chizzotti A. Pesquisa em ciências humanas e sociais. $2^{\mathrm{a}}$ ed. São Paulo: Cortez; 1995

(15) Patton MQ. Enhancing the quality and credibility of qualitative analysis. HSR. 1999;34(5):1189-208.

(16) Chakur SS. Interações e construção do conhecimento no deficiente mental: um estudo na pré-escola e ensino regular. [dissertação]. Campinas: Faculdade de Educação da UNICAMP; 1994.

(17) Cintra FA.A significação do glaucoma e a mediação dos significados da velhice na perspectiva Vygotskiana: subsídios para educação à saúde [tese]. São Paulo: Escola de Enfermagem da USP; 1997.

(18) Gallani MCBJ. Determinantes comportamentais da realização de exercício físico pelo paciente infartado [tese]. São Paulo: Escola de Enfermagem da USP; 2000. 